\title{
Obstructive jaundice at the initial presentation in small-cell lung cancer
}

\author{
This article was published in the following Dove Press journal: \\ International Medical Case Reports Journal \\ 25 February 2010 \\ Number of times this article has been viewed
}

Nobuaki Ochi'
Nagio Takigawa'
Masayuki Yasugi'
Etsuji Ishida'
Hirofumi Kawamoto'
Akihiko Taniguchi'
Daijiro Harada'
Eiko Hayashi'
Hiroko Toda ${ }^{3}$
Hiroyuki Yanai
Mitsune Tanimoto'
Katsuyuki Kiura'
'Department of Hematology,
Oncology and Respiratory Medicine,
'Department of Gastroenterology and
Hepatology, ${ }^{3}$ Department of Pathology
and Oncology, Okayama University
Graduate School of Medicine,
Dentistry and Pharmaceutical
Sciences, Okayama, Japan

Correspondence: Nagio Takigawa

Department of Hematology,

Oncology and Respiratory Medicine,

Okayama University Graduate School of

Medicine, Dentistry and Pharmaceutical

Sciences, 2-5-I Shikata-cho, Okayama,

700-8558, Japan

$\mathrm{Tel}+81862357227$

Fax +81862328226

Email ntakigaw@md.okayama-u.ac.jp

\begin{abstract}
Obstructive jaundice sometimes may develop in association with advanced small-cell lung cancer (SCLC); however, SCLC initially presenting with obstructive jaundice is rare. This report presents the cases of two SCLC patients with obstructive jaundice at the initial diagnosis. A 64-year-old male presented with obstructive jaundice due to a tumor at the head of the pancreas. He was diagnosed with SCLC by transbronchial biopsy from a lung tumor in the left upper lobe. Another 74-year-old male was admitted with jaundice due to a tumor in the porta hepatis. He was also diagnosed with SCLC by a fine-needle aspiration biopsy of a lung tumor in the left lower lobe. Both cases were successfully treated with systemic chemotherapy after endoscopic retrograde biliary drainage.
\end{abstract}

Keywords: small-cell lung carcinoma, jaundice, biliary obstruction, metastasis

\section{Introduction}

Lung cancer is the leading cause of cancer-specific mortality worldwide. Small-cell lung cancer (SCLC) accounts for approximately $13 \%$ of all lung cancer and frequently develops distant metastases. ${ }^{1}$ SCLC potentially causes biliary duct obstruction by metastasizing to lymph nodes in the porta hepatis or the head of the pancreas. The primary sites of secondary tumors in the porta hepatis including the biliary tract, the head of the pancreas, and the ampulla of Vater associated with obstructive jaundice are gastric, colon, and breast cancer in that order. Only $1 \%$ of those tumors originate from lung cancer. ${ }^{2}$ Metastases to the pancreas were found in 26 (3.1\%) of 850 lung cancer patients. ${ }^{3}$ Among 649 autopsy cases, 22 cases of metastases to the pancreas from a primary lung cancer were identified. ${ }^{4}$ Most of them did not present with clinical symptoms due to metastasis of the pancreas. Jaundice usually occurred as a late manifestation of widespread disseminated metastasis. This report presents the cases of two patients presenting with obstructive jaundice without any respiratory symptoms as the initial diagnosis of SCLC.

\section{Case I}

A 64-year-old male who had smoked 90-pack-years presented with obstructive jaundice. He had jaundice and slight abdominal tenderness. The laboratory data were as follows: total bilirubin (T. Bil), $6.62 \mathrm{mg} / \mathrm{dL}$; direct bilirubin (D. Bil), $4.3 \mathrm{mg} / \mathrm{dL}$; aspartate aminotransferase (AST), $85 \mathrm{IU} / \mathrm{L}$; alanine aminotransferase (ALT), 109 IU/L; $\gamma$-glutamyl transpeptidase $(\gamma$-GTP), 813 IU/L; neuron-specific enolase (NSE), $54.5 \mathrm{ng} / \mathrm{mL}$; and pro-gastrin releasing peptide (pro-GRP), $1360 \mathrm{pg} / \mathrm{mL}$. Abdominal 


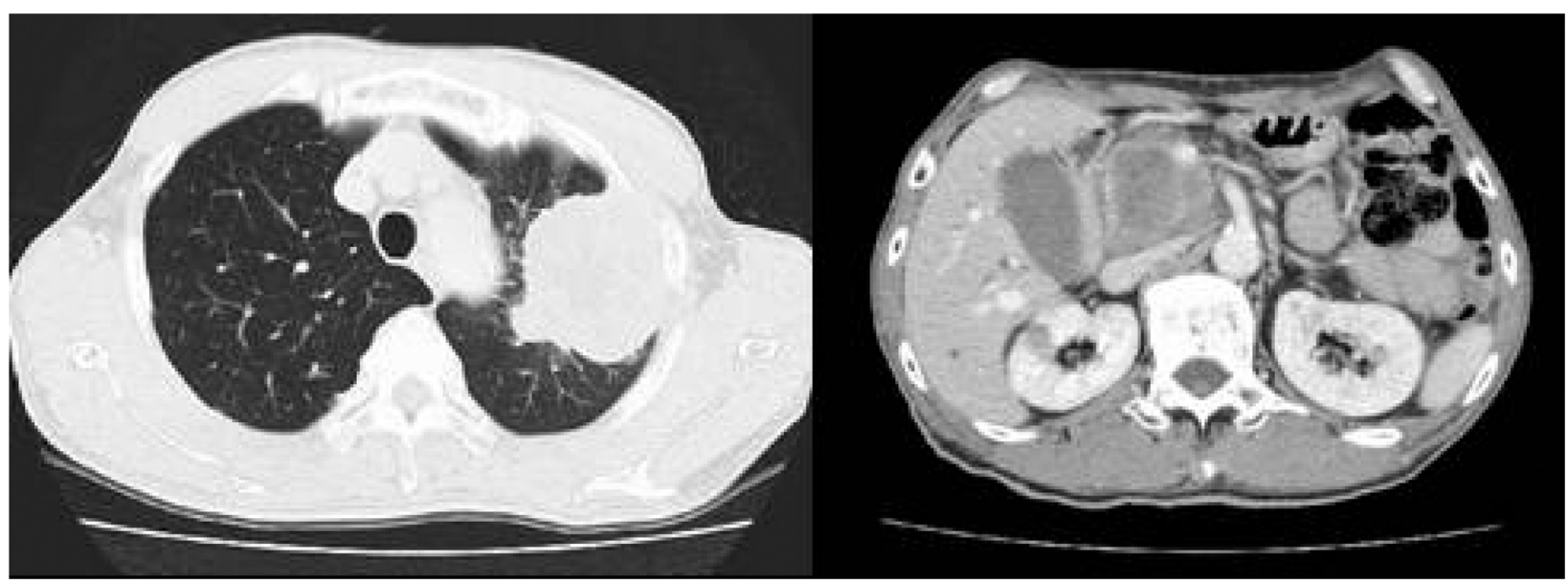

Figure I Tumors in the left upper lobe of the lung (left) and in the porta hepatic (right).

ultrasonography (US) and computed tomography (CT) demonstrated an extrahepatic bile duct obstruction by a tumor at the head of the pancreas (measuring $47 \mathrm{~mm}$ in diameter) and intraabdominal lymph nodes. Chest CT showed a lung tumor in the left upper lobe invading the chest wall and mediastinal lymph nodes swelling (Figure 1). A specimen of a transbronchial biopsy showed SCLC. Finally, he had a diagnosis of extensive stage SCLC (T3N1M1). Endoscopic retrograde biliary drainage (ERBD) relieved the jaundice. He thereafter received combination chemotherapy with cisplatin and topotecan after the level of T. Bil decreased to a normal range. He achieved a partial response with mild toxicity and had survived for 25 months without obstructive jaundice. At autopsy, the ERBD was still effective despite the progression of intraabdominal disease and the pathological specimen of a primary lesion of SCLC (Figures 2a, 2b) showed the same histology as that of the lymph node around the drainage tube (Figures 2c, 2d).

\section{Case 2}

A 74-year-old male with a 27-pack/year smoking history presented with anorexia and jaundice. He had moderate epigastric tenderness. The laboratory findings showed: T. Bil, $9.68 \mathrm{mg} / \mathrm{dL} ;$ D. Bil, $6.37 \mathrm{mg} / \mathrm{dL}$; AST, 479 IU/L; ALT, 587 IU/L; ALP, 1578 IU/L; $\gamma$-GTP, 917 IU/L; NSE, 125 ng/mL; and Pro-GRP, $1790 \mathrm{pg} / \mathrm{mL}$. Abdominal US revealed intrahepatic bile duct dilatation and a tumor of $27 \times 17 \mathrm{~mm}$ located in the parapancreatic head. CT imaging showed swelling of multiple abdominal lymph nodes and a left adrenal gland mass, and a lung tumor measuring $78 \times 51 \mathrm{~mm}$ located in the left lower lobe (Figure 3). Swelling of the contralateral and ipsilateral mediastinal lymph nodes was also detected.
A specimen of a fine-needle aspiration biopsy from the lung tumor confirmed the diagnosis of SCLC. Multiple brain metastases were detected by magnetic resonance imaging. He had a diagnosis of extensive stage SCLC (T4N3M1). He had hyponatremia $(111 \mathrm{mEq} / \mathrm{l})$ due to inappropriate antidiuretic hormone secretion by SCLC. He underwent combination chemotherapy with carboplatin and etoposide after ERBD relieved the jaundice and the T. Bil level was reduced to $1.42 \mathrm{mg} / \mathrm{dL}$. He achieved a partial response; however, the SCLC progressed rapidly and he died after four months.

\section{Discussion}

This report described two SCLC patients with obstructive jaundice at the initial presentation that were treated with systemic chemotherapy after ERBD. Only 11 cases of SCLC initially presenting obstructive jaundice have been reported. ${ }^{5-11}$ According to the oldest known report described by Dunkerley and colleagues in 1976, local radiation therapy was administered. ${ }^{5}$ In 1985, Johnson and colleagues described five patients that initially received systemic chemotherapy. ${ }^{6}$ Martin and colleagues also described one case that unfortunately died due to a sudden cardiac arrest before any treatment could be performed. ${ }^{7}$ One of the four more recent patients underwent surgery followed by chemotherapy, ${ }^{8}$ one underwent surgery alone, ${ }^{9}$ and two patients were treated with percutaneous transhepatic biliary drainage (PTBD) followed by chemotherapy. ${ }^{10,11}$ The patients in the current study were treated with ERBD before chemotherapy. ERBD is widely used for drainage of distal bile duct obstructions and PTBD is employed in difficult cases of ERBD. ${ }^{12}$ Obstructive jaundice by metastasis of SCLC should be noted even at the initial diagnosis because SCLC is highly sensitive to chemotherapy. 

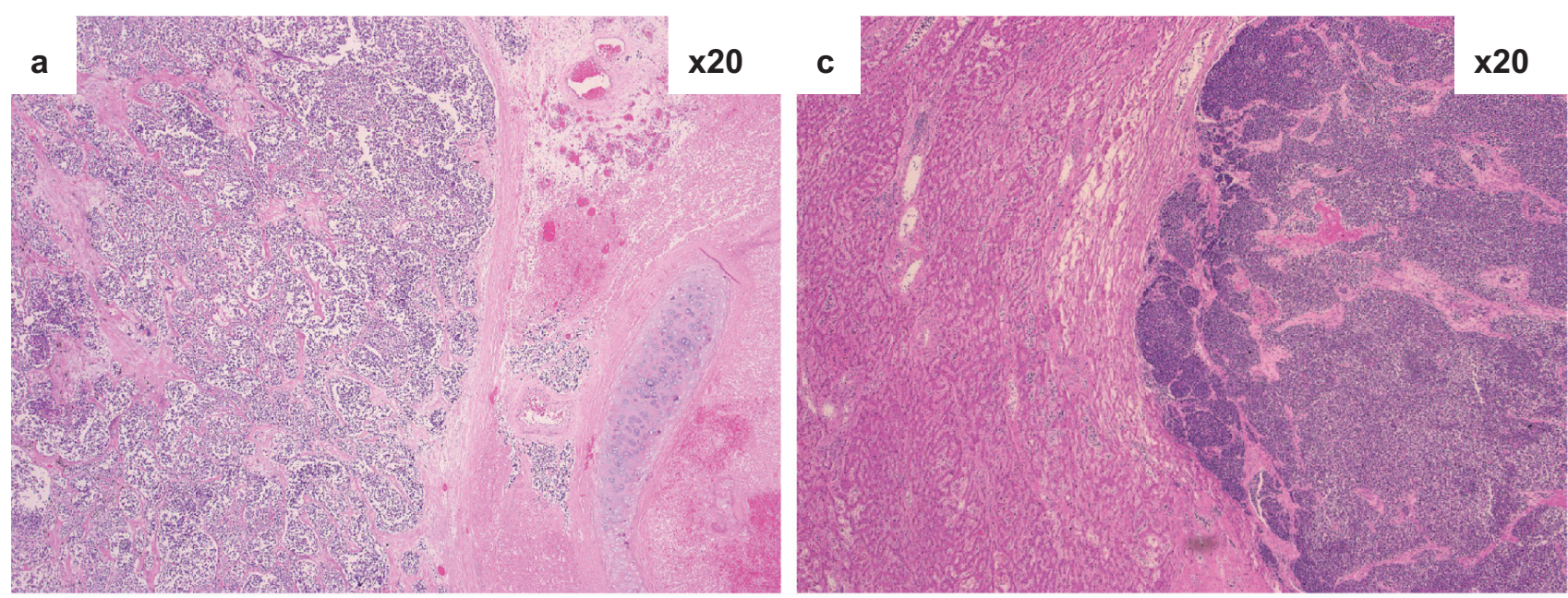

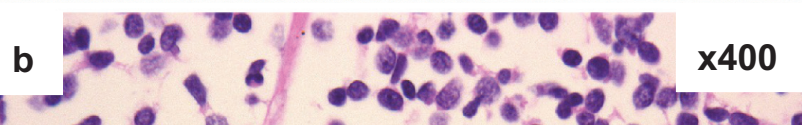

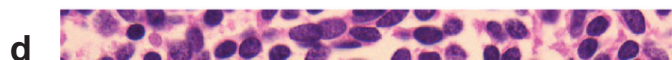

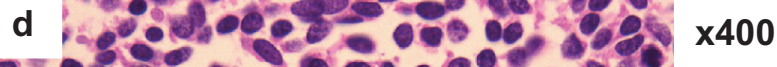

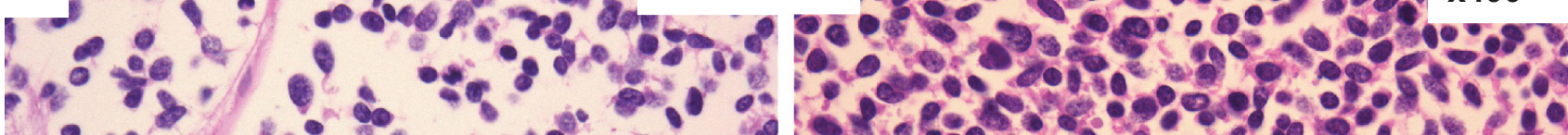
8. $0^{\circ}$. LE.

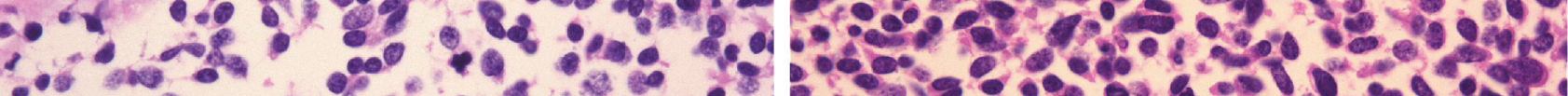

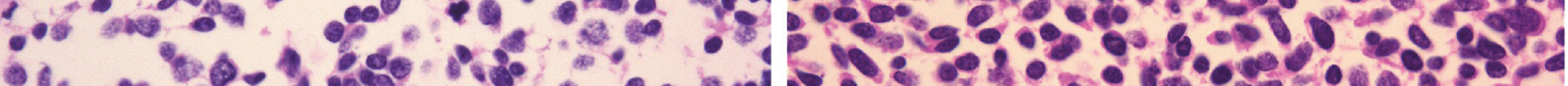

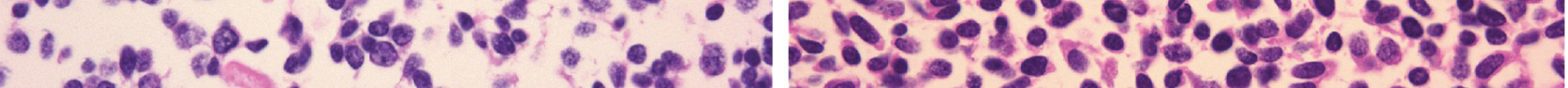

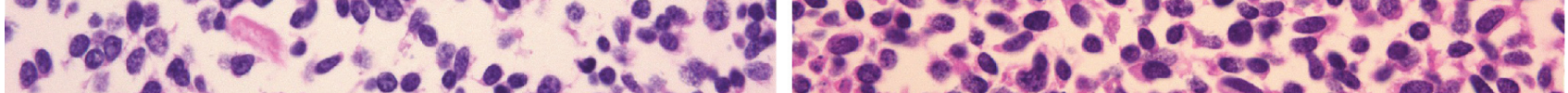

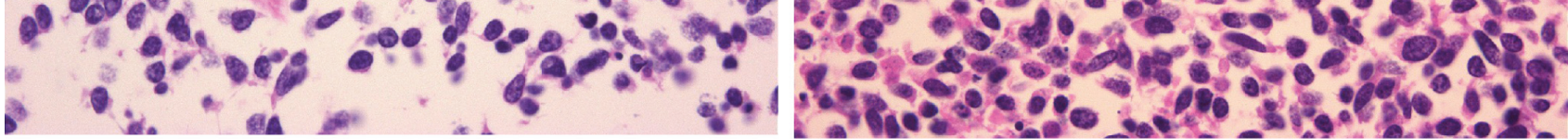

Figure 2 Histology of the primary lung lesion $(\mathbf{a}: \times 20, \mathbf{b}: \times 400)$ and metastatic lymph node around the drainage tube $(\mathbf{c}: \times 20, \mathbf{d}: \times 400)$.
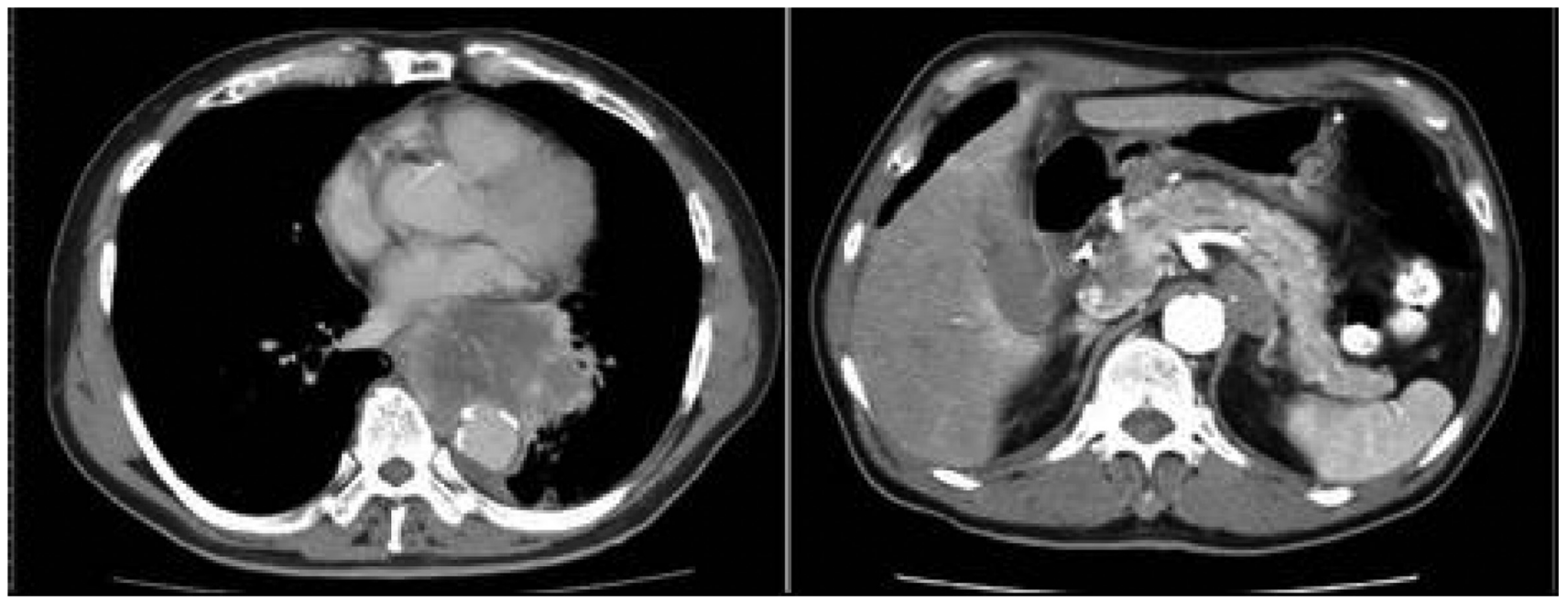

Figure 3 Tumors in the left lower lobe of the lung (left) and in the parapancreatic head (right) 


\section{Disclosures}

The authors report no conflicts of interest in this work.

\section{References}

1. Govindan R, Page N, Morgensztern D, et al. Changing epidemiology of small-cell lung cancer in the United States over the last 30 years: analysis of the surveillance, epidemiologic, and end results database. J Clin Oncol. 2006;24:4539-4544.

2. Lokich JJ, Kane RA, Harrison DA, McDermott WV. Biliary tract obstruction secondary to cancer: management guidelines and selected literature review. J Clin Oncol. 1987;5:969-981.

3. Maeno T, Satoh H, Ishikawa H, et al. Patterns of pancreatic metastasis from lung cancer. Anticancer Res. 1998;18:2881-2884.

4. Matsukuma S, Suda K, Abe H, Ogata S, Wada R. Metastatic cancer involving pancreatic duct epithelium and its mimicry of primary pancreatic cancer. Histopathology. 1997;30:208-213.

5. Dunkerley RC, Dunn GD. Use of retrograde cholangiography in guiding radiotherapy of obstructive jaundice due to tumor. Am J Gastroenterol. 1976;66:283-286.
6. Johnson DH, Hainsworth JD, Greco FA. Extrahepatic biliary obstruction caused by small-cell lung cancer. Ann Intern Med. 1985;102:487-490.

7. Martin A, Castagliuolo I, Mastropaolo G, et al. Cholestatic jaundice as the presenting symptom of small-cell lung cancer. Ital J Gastroenterol. 1990;22:36-39.

8. Kotan C, Er M, Ozbay B, Uzun K, Barut I, Ozgoren E. Extrahepatic biliary obstruction caused by small-cell lung cancer: a case report. Acta Chir Belg. 2001;101:190-192.

9. Sakar A, Kara E, Aydede H, Ayhan S, Celik P, Yorgancioğlu A. A case of a small-cell lung carcinoma presenting with jaundice due to pancreatic metastasis. Tuberk Toraks. 2005;53:181-184.

10. Obara M, Satoh H, Yamashita YT, et al. Metastatic small-cell lung cancer causing biliary obstruction. Med Oncol. 1998;15:292-294.

11. Jeong IB, Kim SM, Lee TH, et al. Pancreatic metastasis and obstructive jaundice in small-cell lung carcinoma. Korean J Intern Med. 2006;21: $132-135$.

12. van Delden OM, Laméris JS. Percutaneous drainage and stenting for palliation of malignant bile duct obstruction. Eur Radiol. 2008;18: $448-456$.
International Medical Case Reports Journal

\section{Publish your work in this journal}

The International Medical Case Reports Journal is an international, peer-reviewed open-access journal publishing original case reports from all medical specialties. Previously unpublished medical posters are also accepted relating to any area of clinical or preclinical science. Submissions should not normally exceed 2,000 words or

\footnotetext{
Submit your manuscript here: http://www.dovepress.com/international-medical-case-reports-journal-journal
}

4 published pages including figures, diagrams and references. The manuscript management system is completely online and includes a very quick and fair peer-review system, which is all easy to use. Visit http://www.dovepress.com/testimonials.php to read real quotes from published authors. 